\title{
INNOVATION AND COMMUNICATION TECHNOLOGIES (ICT) AS A SUPPORT FOR THE DEVELOPMENT AND PROMOTION OF CREATIVE THINKING PROCESSES IN UNIVERSITY TEACHING
}

\author{
M.I. Alba Dorado \\ University of Malaga (SPAIN)
}

\begin{abstract}
Nowadays, we are attending an expansion of the Innovation and Communication Technologies (ICT) in various aspects of life, including the teaching one. In the same way, we observe how the importance of the creativity's role has increased, being declared one of the most important skills in the educational context of the 21st century. The importance of this creative component in the formation of people entails a completely new approach to teaching. Nowadays, teaching can use many means to enhance the development of creativity formulated through educational objectives. Among these diverse means, technological, audiovisual and computer tools occupy a privileged place.

Innovation and Communication Technologies (ICT), due to its multidimensional nature, can offer numerous ways to enhance the development of creativity. These innovative didactic tools generate a high motivating potential due to their great appeal, and they constitute a propitious occasion to provoke significant learning.

In this sense, the main objective of this paper is to reflect on those educational strategies that improve the teaching of university teaching staff based on the use of ICTs in the teachinglearning process from an enriching perspective, as well as making the most of the opportunities that these resources provide not only for the achievement of pedagogical objectives or the improvement of student learning, but also to encourage and develop their creativity. To do so, it is proposed to reflect on a training model that supports, through these technological tools, a proactive approach to creativity in the classroom that includes the presence of favorable attitudes on the part of the teacher and the development of skills related to the thinking and the creative behavior in the students.
\end{abstract}

Keywords: Innovation and Communication Technologies, Creativity, Architecture. 